CAT 2010 London Conference $\sim 3^{\text {rd }}$ February

Maria Chatzichristodoulou [aka Maria X]

\title{
CURATING TECHNOCULTURES [2010]
}

\author{
Maria Chatzichristodoulou [aka Maria X] \\ School of Arts and New Media \\ University of Hull (Scarborough campus) \\ Filey Road, YO11 3AZ \\ Scarborough, North Yorkshire \\ U.K. \\ Email: M.Chatzi@hull.ac.ik \\ URL: http://www.hull.ac.uk/sanm/
}

This paper sets out to discuss issues of curation of media arts and other emergent technologised practices (e.g. digital performance). Through examining a range of media art festivals, exhibitions and events from the 1990s to 2010, this paper will argue against the curation of media arts as practices that are divorced from the contemporary arts scene. I will suggest that this curatorial approach of positive discrimination can lead to: a) establishing emergent technologised practices as peripheral to other, often more popular or mainstream, (sub-)cultures (and thus markets) and, b) technological determinism (in this case, focus on the technologies at the expense of content, social impact and/or affect).

In 1998 I co-founded, with Manthos Santorineos (Associate Professor, Athens School of Fine Arts), the $1^{\text {st }}$ Hellenic Art and Technology Festival (HATF) in Athens, Greece. A year later the festival expanded to become international with a focus on the area of Southeast Europe and the Mediterranean, and was renamed Medi@terra. Its aim was to showcase the (at the time) emergent field of media arts. This was the first time a large-scale event in Greece had brought together arts and emergent technologies. The festival embraced a range of artistic practices, which, until that time, had no place within the Greek contemporary art scene. HATF did not have an overarching theme: it simply invited, through a call for projects, artistic practices that integrated digital technologies, and it/we commissioned works along the same lines.

The fields under which we invited works for submission were defined in relation to the different formats the projects could take, such as: interactive installations (for interactive projects which manifest themselves, in one way or another, as objects or environments within physical space), animation and video art (for screen-based works), net.art (for projects that exist solely online), CD-ROM art (for digital projects that exist off-line), digital photography and print (for digital imaging works) and sound art (for digital sound/music works). At the time several 'media/digital art' festivals were taking place, such as Ars Electronica (Linz, Austria), [1] Inter-Society for Electronic Arts (international organisation based in Canada, nomadic event), [2] 
CAT 2010 London Conference $\sim 3^{\text {rd }}$ February

Maria Chatzichristodoulou [aka Maria X]

Transmediale (Berlin, Germany), [3] European Media Art Festival (Osnabrueck, Germany), [4] Dutch Electronic Arts Festival (Rotterdam, Netherlands), [5] VIPER (Basel, Switzerland) [6] and Multimedia Arts Asia Pacific [7] among others. Several of these festivals, such as Ars Electronica and Transmediale, still thrive today (2009).

The approach favoured by the $1^{s t} H A T F$, that is, inviting works on the basis of their format and media rather than content or subject-matter, was in accord with the international media arts community: all the above mentioned festivals also did (and still do) invite works on a similar basis, thus generating taxonomies within which the emergent artistic practices we were aiming to showcase could be 'neatly' categorised. Throughout the (brief) history of the genre, these taxonomies have primarily focused on the format of the work, the way the work manifests itself within the physical domain, and the technologies employed, rather than the qualitative issues of concept, content, and dramaturgy (in relation to interactive artworks which are performative in their nature). Such taxonomies were, I think, strengthened when Christiane Paul's book Digital Art was published in 2003. In this, Paul argues:

It is problematic to claim that all digital artworks can be neatly categorized according to different forms: most of the time, these works combine various elements (...) and defy a purely formal classification. Nevertheless, it is important to be aware of the formal aspects upon which the art is based. Ultimately, every object -even the virtual one- is about its own materiality, which informs the ways in which it creates meaning. Among the forms that a digital artwork can take are installation; film, video, and animation; Internet art and software art; and virtual reality and musical environments. [8]

The forms that Paul identifies are not identical to the ones identified by the $1^{\text {st }}$ HATF. Indeed, such discrepancies have been common across the field, as formal categories are subject to constant change, updating and revisiting (following new practices but also signifying differing curatorial approaches). For example, the $1^{\text {st }} H A T F$ did not include 'film' as a form in its call: we considered film to be an older medium that was already being showcased elsewhere. It did not include virtual reality environments either, but this was due to the technical requirements of such artworks: in order to showcase a virtual reality environment we would have needed to acquire and install a VR system (such as a CAVE, for example).

These were particularly costly at the time, and people with the technical knowledge and expertise required to install and operate this technology were few and far between (Medi@terra 2000 did include VR works in the Call, as we were able to use the Hellenic Institute's newly installed CAVE system). Despite discrepancies in formal categories, one thing was consistent across the international community of media arts festivals: they all invited works invested in emergent technologies -other, nontechnologised types of artworks did not normally have a place within these contexts- 


\section{CAT 2010 London Conference $\sim 3^{\text {rd }}$ February \\ Maria Chatzichristodoulou [aka Maria X]}

and they mostly did so through categorising the works on the basis of formal rather than conceptual, aesthetic, social or other criteria (I should point out that this approach of positive discrimination was possibly justified at the time, as media arts were rarely represented within more mainstream contemporary art contexts).

In 2002 Sergey Teterin (director), Olga Goriunova (curator) and Alexei Shulgin (consultant, curator) launched in Moscow (Russia) the read me festival 1.2 on software art and software art games. Read_me 1.2 was the first festival "dedicated to the artistic contemplation of software: its creation, modification and deconstruction." [9] The organisers of read_me 1.2 festival went on to develop Runme.org: an open, moderated database where people were invited to submit software art projects. [10] The next edition of the festival, read_me 2.3, took place the following year (2003) in Helsinki, based on the Runme.org database. [11] At the time I found Runme.org and read_me 2.3 striking due to their exceptional structure: Runme.org was structured both "taxonomically/rationally (category list) and intuitively (keyword cloud)". [12]

The category list was more expansive than most and ran as follows (these are only the main categories; each category featured several sub-categories; numbers in parenthesis indicate the amount of projects submitted under each category):

algorithmic appreciation (2)

appropriation and plagiarism (5)

artificial intelligence (10)

artistic tool (39)

bots and agents (15)

browser art (19)

code art (21)

conceptual software (31)

data transformation (34)

digital aesthetics $r \& d(9)$

digital folk and artisanship (18)

existing software manipulations (7) 
games (15)

generative art (48)

hardware transformation (7)

installation-based (6)

institutional critique (7)

performance-based (10)

political and activist software (25)

social software (5)

software cultures - links (15)

system dysfunctionality (10)

text - software art related (47)

text manipulation (36)

Read_me was targeting works of a very specific genre, that is, works that could be approached as artistic software. Nonetheless, what this list of categories makes clear is that taxonomies, though 'rational', were generated on the basis of not only formalist but also conceptual criteria: for example, the categories 'political and activist software' and 'social software' taxonomise works in relation to their social and political agendas and impact, rather than the technologies employed or the way projects manifest themselves in space. Even more intriguing to me at the time was the intuitive approach (word cloud), which existed side by side with the taxonomical one. This was as follows:

\begin{tabular}{|l|l|l|l|l|l|l|}
\hline $1960 \mathrm{~s}$ & collaboration & film & junk & open_source & psychiatric & surreal \\
\hline $1980 \mathrm{~s}$ & collaborative & flash & knitting & outsource & python & surveillance \\
\hline $1990 \mathrm{~s}$ & community & \multicolumn{1}{|l}{ folk } & labor & P2P & radio & symbiosis \\
\hline 1996 & conceptual & lawyer_resistant & paranoid & random & symmetry & formalist \\
\hline 1997 & consciousness & found_object & lingo & parodyware & realtime & synesthesia \\
\hline $3 \mathrm{~d}$ & constraints & fractal & linux & pascal & realworld & system \\
\hline abstract & copyright & fragile & lisp & passionate & relaxing & talking \\
\hline abuse & corruption & free_software & literary & patterns & religious & taskbar \\
\hline active & countercultural & friendly & live & performance & remix & telematic \\
\hline
\end{tabular}


CAT 2010 London Conference $\sim 3^{\text {rd }}$ February

Maria Chatzichristodoulou [aka Maria X]

\begin{tabular}{|c|c|c|c|c|c|c|}
\hline aesthetics & crash & frustrated & live_coding & performative & representation & templates \\
\hline algorithmic & criticism & gadgety & love & perl & robot & terrorism \\
\hline amiga & cute & generative & lowtech & philosophical & RSS & text \\
\hline anachronistic & cyborg & genetic & $\mathrm{mac}$ & photography & sampling & trash \\
\hline anti_information & dada & glitch & manifesto & PHP & scary & trivial \\
\hline anthropomorphic & dangerous & goofy & Mapping & pixel & scientific & turing \\
\hline apocalyptic & database & Google & market & plagiaristic & screensaver & tv \\
\hline archetype & death & hackerly & marxist & playing & semantic & typing \\
\hline archive & debate & hardware & mathematical & pocket_pc & seminal & unix \\
\hline ascii & deconstructive & $\mathrm{HCI}$ & meme & poetry & serendipitous & unnoticeable \\
\hline atari & decorative & historical & messaging & political & serial & useless \\
\hline audiovisual & design & hoax & metaphorical & pop_culture & sexy & utility \\
\hline authorship & desktop & html & metaphysical & porn & sharing & vectorial \\
\hline automata & dhtml & identity & MIDI & positive & simulation & video \\
\hline automation & disturbing & illegal & mindware & posix & sinclair & violence \\
\hline backwards & dos & illustration & minimalistic & post dotcom & sing & virtual \\
\hline BBS & drugs & imagery & mobile & postscript & smiley & virus \\
\hline beos & dysfunctional & information & modal & power & social & visual \\
\hline binary & eccentric & installation & montage & pragmatic & sound & voice \\
\hline blog & ecological & instructive & multiuser & presence & spam & voyeur \\
\hline body & & educational & interactive & musical & privacy & speech \\
\hline $\mathrm{c}$ & efficient & interface & network & probability & stimulation & windows \\
\hline c64 & email & intuitive & neural_net & process & storytelling & $\operatorname{xxxxx}$ \\
\hline capitalism & error & irc & news & productivity & stream & \\
\hline chaos & evangelist & ironic & noisy & programming & subjectivity & \\
\hline chat & feedback & iterative & nude & propaganda & subversive & \\
\hline code & feminist & java & obfuscated & provocative & supernatural & \\
\hline coding & filesharing & javascript & on line & psychedelic & superstitious & \\
\hline
\end{tabular}

[14]

I consider Runme/read_me, from a curatorial perspective, as revolutionary in its approach: it constituted the first attempt to question rigid formal categories in media arts and challenge the way curators and, possibly, artists thought about their works; at the same time, the festival did acknowledge the necessity and functionality of taxonomic systems and the near impossibility of abandoning them completely. Runme/read me's approach is a playful and pertinent criticism of the long-standing attempts of curators and event organisers to neatly classify and formally categorise emergent fields of practice. The festival's intuitive structure succeeded in exposing the rigidity (and often absurdity) of such formal categories as well as the lack of 


\section{CAT 2010 London Conference $\sim 3^{\text {rd }}$ February \\ Maria Chatzichristodoulou [aka Maria X]}

engagement with issues of content, social value and affect in the way festivals and showcases invited works for submission or commissioned new work.

Despite its attempt to question and unsettle formal categories for studying and presenting media arts, Runme/read_me remained firmly rooted within the tradition of presenting this emergent field of practice as independent from (peripheral to?) more mainstream contemporary art practices. As a result, although formal categories within the field were imaginatively challenged, the festival itself remains classified as a media arts festival, without any attempt to shake this (formalist) distinction (I do not intend this as a judgment on the cultural value and success of the event). I will go on to examine Read_me/Runme.org's heritage today in relation to the curation of media arts and other emergent, technologised, practices.

\section{References}

[1] Ars Electronica website. Available from: http://www.aec.at [accessed 20/04/09]

[2] ISEA website. Available from: http://www.isea-web.org/ [accessed 20/04/09]

[3] Transmediale website. Available from: http://www.transmediale.de/ [accessed 20/04/09]

[4] European Media Art Festival website. Available from: http://www.emaf.de/ [accessed 20/04/09]

[5] $D E A F$ website. Available from: http://www.deaf07.nl/index.php?option=com_content\&task=view\&id=11\&Item id=1 [accessed 20/04/09]

[6] VIPER website. Available from: http://www.viper.ch/2006/content/main.php [accessed 20/04/09]

[7] Multimedia Arts Asia Pasific website. Available from: http://www.maap.org.au/ [accessed 20/04/09]

[8] PAUL, C: Digital Art. 2003 London and New York, Thames and Hudson, p. 70.

[9] Read me festival 1.2 website available from: http://readme.runme.org/1.2/abouten.htm 2002 [accessed 21/04/2009]. Read_me festival 1.2. Organizers. Available from: http://readme.runme.org/1.2/feeden.htm 2002 [accessed 21/04/2009]

[10] Runme.org was a collaborative, open project developed by Amy Alexander, Florian Cramer, Matthew Fuller, Olga Goriunova, Thomax Kaulmann, Alex McLean, Pit Schultz, Alexei Shulgin, and The Yes Men. Runme.org website. Available from: http://runme.org/about.tt2 2003 [accessed 21/04/2009]

[11] Read_me festival 2.3 website. Available from: http://www.m-cult.org/read_me/ 2003 [accessed 21/04/2009]

[12] Runme.org. About. Available from: http://runme.org/about.tt2 2003 [accessed 21/04/2009]

[13] Runme.org. Categories. Available from: http://runme.org/categories/ 2003 [accessed 21/04/2009]

[14] Runme.org. Keywords. Available from: http://runme.org/keywords/ 